\title{
Sugar Content in UK Breakfast Cereals: A Market Survey
}

\section{Abstract}

Breakfast cereals are known to provide a nutrient-dense meal and are a useful source of carbohydrate, fibre and micronutrients. However, in the UK cereal products are the primary contributor of free sugars in the diets of children aged 1.5 to 10 years; and are the second leading source of free sugars in children aged 11 to 18 years and adults aged 19 to 64 years. For this reason, breakfast cereals were included among food items recommended by the UK government for a $20 \%$ reduction in sugar by 2020 for childhood obesity prevention. Therefore, this study aimed to investigate the nutrient contents, including sugars, of breakfast cereals sold in the $\mathrm{UK}$, in particular those marketed to children. Nutritional information and ingredients of cereal products available in five major online supermarkets in the UK, in 2018, were collected into a comprehensive database for analysis. A systematic process flow approach was utilised to separate products into nine distinct categories. Children's products were stratified both on being wholegrain rich $(\geq 50 \%$, WG) or not (NWG), and on total sugar content; with $>12.3 \mathrm{~g} / 100 \mathrm{~g}$ defined as 'highly flavoured and sweetened' (HFS) versus 'plain' containing $\leq 12.3 \mathrm{~g} / 100 \mathrm{~g}$ (the target set by the UK for industry sugar reduction). Of the 757 unique products surveyed, 97 cereals were categorised as children's. Cereals not explicitly marketed to children were categorised as either 'family favourites' (containing $<50 \%$ wholegrains), 'free-from and organic', 'porridge and oats', 'healthier with dried fruits', or 'healthier without dried fruits' (healthier defined as wholegrain rich, $\geq 50 \%$ ). Children's HFS products $(\mathrm{n}=78)$ contained by far the highest sugar contents of all cereals examined. While there was no difference in total sugar between NWG/HFS $(\mathrm{n}=69$, median [range]: $29.0 \mathrm{~g} / 100 \mathrm{~g}$ [12.4, 41.0]) and WG/HFS $(\mathrm{n}=9,22.0 \mathrm{~g} / 100 \mathrm{~g}[13.6,26.0])$ cereals; these were much higher $(P<0.01)$ than the median sugar contents $(8.8-19.0 \mathrm{~g} / 100 \mathrm{~g})$ observed in the other seven product categories. Children's NWG cereals contained dramatically lower fibre (NWG/HFS: 3.5 [0, 8.7], NWG/Plain: $1.6 \mathrm{~g} / 100 \mathrm{~g}[1.3,7.2])$ than all other product categories $(7.3-9.1 \mathrm{~g} / 100 \mathrm{~g} ; P<0.001)$. Similarly, NWG/HFS cereals were lower in protein content $(7.4 / 100 \mathrm{~g}[3.6,17.2])$ than the non-children's cereals $(8.8-11 \mathrm{~g} / 100 \mathrm{~g} ; P<0.05)$. In conclusion, children's categories of cereal contain significantly greater amounts of sugar and lower amounts of fibre and protein than other cereal categories. Despite their fortification with vitamins and minerals, reformulation of this food category should be a priority alongside additional sugar-reducing strategies.

\section{Conflict of Interest}

There is no conflict of interest 